\title{
PROPOSAL FOR INTEGRATING AN EDI CLOUD SOLUTION INTO THE INFORMATION SYSTEM STRUCTURE AT A METALLURGICAL ENTERPRISE
}

\author{
${ }^{1}$ Martin LAMPA, ${ }^{2}$ Pavla KONFRŠTOVÁ, ${ }^{3}$ Andrea SAMOLEJOVÁ \\ ${ }^{1}$ VSB - Technical University of Ostrava, Ostrava, Czech republic, EU, \\ martin.lampa@vsb.cz, pavla.konfrstova.st@vsb.cz, andrea.samolejova@vsb.cz
}

https://doi.org/10.37904/metal.2020.3658

\begin{abstract}
Electronic information transfer has existed for decades, and the many advantages of this type of communication are employed by large companies where quick, flawless and secure data transfer is essential. Many companies use advanced information systems internally, hence most of their documents are created in electronic format. It could therefore be said that for companies to exchange documents in hardcopy or via email and manually file these documents is an anachronism. If a company decides to take advantage of more modern data transfer technology, this is often more a necessity rather than a competitive advantage if the enterprise wants to remain relevant to key customers or suppliers.

The aim of the article was to identify the suppliers and customers who would be ideal to implement joint EDI communications with, predict the efficiency and speed of purchasing and sales processes, recommend the broader use of EDI communication integration, evaluate the advantages and disadvantages of implementing EDI, and subsequently propose a suitable EDI cloud solution to integrate with the information system at a metallurgical enterprise.
\end{abstract}

Keywords: EDI, information system, purchasing, sales

\section{INTRODUCTION}

This is a key component of electronic trade and forms a part of almost all sectors of commerce. Not long ago, electronic trade was considered somewhat revolutionary in business administration [1].

When this form of trade began, its essence was very simple. Even today, products, goods or services can be traded directly and very simply with only pencil and paper. Even a computer at a simple level is an electronic version of paper and pen, but of course, much faster and more advanced [2]. Over time, banks began to intervene in this form of trade to manage finance, as did public authorities and courts to maintain correct fulfilment of contracts. This significantly complicated trade. Moreover, the demands on the speed and volume of trade keep rising [3].

All these needs, which include more than speed, security and economy, are fulfilled by electronic data transfer. The stakeholders in electronic trade processes intervene only sporadically, the need to rewrite documents into corporate systems ceases to exist, and communications between two systems become automated (communication and document exchange scheme is shown in Figure 1).

The abbreviation EDI comes from the term in English: Electronic Data Interchange. In a broader sense, this means the electronic interchange of standard structured business and other documents or messages between two applications of two independent entities, which means the exchange of data in the same form in a unified "language" between the applications of two independent business partners. EDI initially automated the interchange of documents, such as orders, invoices, delivery notes and shipping documents [4]. Although some companies still use EDI for document automation, companies involved in the principle of Just-In-Time supply and non-stop production use EDI as a system for continuous supply [5]. Suppliers have direct access to selected sections of purchasing for production and scheduled deliveries and can automate dispatch of materials and goods to fulfil prescribed procedures without any intervention from company managers. 

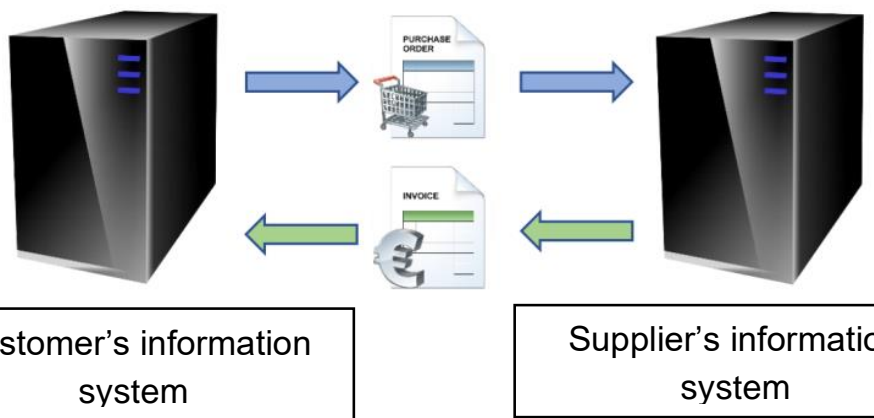
Customer's information system

Supplier's information system

Figure 1 Simplified diagram of EDI document exchange

\section{SELECTION OF SUITABLE ENTITIES TO IMPLEMENT THE EDI COMMUNICATION PROCESS}

The corporate system studied in this article includes approximately 2,900 supplier and 5,000 active customer entities. Of these almost 8,000 entities, just under 1,900 are registered simultaneously as a supplier and customer. Only several entities will be selected for EDI implementation. An introduction to the communications process would be fundamentally relevant to these entities regarding time and costs savings and reduce the error rate in manual document entry.

The main criteria for selecting suitable entities to implement EDI communications are:

a) Entities with a high number of entered invoices;

b) Entities with a high number of entered items in one invoice;

c) Entities with high invoicing values.

According to the above criteria, eight entities were selected, two being both suppliers and customers of the company Dileris. The specific data of the individual criteria for each of the selected entities are given in Tables 1, 2.

Table 1 Values and volume of invoices of the entities selected for EDI in 2018 (in CZK)

\begin{tabular}{|c|c|c|c|c|c|c|c|}
\hline \multirow[t]{2}{*}{ Entity } & \multirow[t]{2}{*}{2018} & \multicolumn{2}{|c|}{ Purchase } & \multicolumn{2}{|c|}{ Sale } & \multicolumn{2}{|c|}{$\begin{array}{c}\text { Average number of } \\
\text { items per invoice } \\
\text { (units) }\end{array}$} \\
\hline & & $\begin{array}{l}\text { Invoice value } \\
\text { (mil.) }\end{array}$ & Invoice quantity & $\begin{array}{l}\text { Invoice value } \\
\text { (mil.) }\end{array}$ & $\begin{array}{l}\text { Invoice } \\
\text { quantity }\end{array}$ & Purchase & Sale \\
\hline A & & 3.2 & 701 & 407 & 125 & 2 & 55 \\
\hline $\mathrm{B}$ & & & & 15 & 33 & & 45 \\
\hline C & & & & 8.5 & 16 & & 10 \\
\hline $\mathrm{D}$ & & & & 4.4 & 125 & & 4 \\
\hline$E$ & & 355 & 3,983 & 2.7 & 172 & 25 & 6 \\
\hline $\mathrm{F}$ & & 44 & 733 & & & 20 & \\
\hline$G$ & & 10.5 & 313 & & & 8 & \\
\hline $\mathrm{H}$ & & 6.1 & 72 & & & 7 & \\
\hline \multicolumn{2}{|c|}{ Total for selected entities } & 418.8 & 5,802 & 437.6 & 471 & & \\
\hline \multicolumn{2}{|c|}{ Total for all entities } & 451 & 8,711 & 509 & 6,388 & & \\
\hline
\end{tabular}


Table 2 Values and volume of invoices of entities selected for EDI in 2019 (in CZK)

\begin{tabular}{|c|c|c|c|c|c|c|c|}
\hline \multirow[t]{2}{*}{ Entity } & \multirow[t]{2}{*}{2019} & \multicolumn{2}{|c|}{ Purchase } & \multicolumn{2}{|c|}{ Sale } & \multicolumn{2}{|c|}{$\begin{array}{c}\text { Average number of items } \\
\text { per invoice (units) }\end{array}$} \\
\hline & & $\begin{array}{c}\text { Invoice } \\
\text { value (mil.) }\end{array}$ & $\begin{array}{l}\text { Invoice } \\
\text { quantity }\end{array}$ & $\begin{array}{c}\text { Invoice } \\
\text { value (mil.) }\end{array}$ & $\begin{array}{l}\text { Invoice } \\
\text { quantity }\end{array}$ & Purchase & Sale \\
\hline A & & 2.8 & 569 & 518 & 189 & 2 & 50 \\
\hline $\mathrm{B}$ & & & & 6 & 10 & & 40 \\
\hline $\mathrm{C}$ & & & & 0.75 & 2 & & 4 \\
\hline $\mathrm{D}$ & & & & 1.2 & 24 & & 4 \\
\hline$E$ & & 409 & 1,861 & 2.3 & 169 & 20 & 6 \\
\hline $\mathrm{F}$ & & 38 & 609 & & & 20 & \\
\hline $\mathrm{G}$ & & 10 & 452 & & & 10 & \\
\hline $\mathrm{H}$ & & 2.5 & 30 & & & 6 & \\
\hline \multicolumn{2}{|c|}{ Total for selected entities } & 462.3 & 3,521 & 528.25 & 394 & & \\
\hline \multicolumn{2}{|c|}{ Total for all entities } & 495 & 6,190 & 610 & 5,755 & & \\
\hline
\end{tabular}

\section{Purchases and sales \\ Purchases or sales}

All eight entities were asked whether they were EDI ready, i.e. connected to EDI communication, and all eight entities responded affirmatively. Two of these eight entities are business partners who exchange purchasing and sales documents with clients, specifically clients $A$ and $E$. These two entities also have the highest number of entered purchase invoices and almost the highest number of sales invoices.

The average number of items per invoice was also determined for the needs of the EDI provider. This information is also shown in the tables.

For clarity, the tables above also mention the total value and volume of invoices in the purchasing and sales documents issued to all entities in 2018 and 2019. The total number of entities invoiced in the individual years is also shown in the tables.

Tables 1, 2 show that the implementation of EDI would have the greatest effect on purchasing documents. The quantity of these documents in both listed years is higher than that of sales documents and covers most of the purchasing documents overall.

The tables above also indicate that in both years, purchases and sales with selected entities reached majority values compared to the total value of issued documents. Concerning the quantity of documents, over half of the purchase documents in both years were entered for five of the aforementioned entities. A significant difference is evident in the number of sales documents, caused by a large number of documents issued for small amounts. This claim is also corroborated by information regarding the number of entities invoiced in both years. It is clearly evident from the tables that an average of CZK 80 million is dispersed across more than 5,500 sales documents, at approximately the same ratio in both years.

\section{SELECTION OF A SUITABLE EDI SOLUTION}

An EDI solution called ORiON produced by the company GRiT was selected for integration into the existing information system after consideration of price, the company's experience with implementation, and discussions with their sales representatives. 
Exchanging a large number of documents, the electronic document flow runs directly with the corporate system, users work directly with the documents in the system as they are accustomed to doing, and no need arises to rewrite them manually. A requirement is an EDI bridge (plug-in) which allows the information system to connect to the EDI provider.

ORiON EDI has currently resolved connections with over 150 information systems in the Czech Republic and Slovakia and has more than 2000 partners.

The ORiON system's advantage is that it uses a large number of related services which GRiT offers through the platform. Among the most interesting of these are the ORiON data mailbox, payment by Roger, insolvency monitoring, electronic catalogues, and a mobile application which can track received orders from a mobile phone or tablet.

For the metallurgical company, the greatest advantage of the ORiON solution is the existing cooperation between GRiT and the affiliates of the metallurgical enterprise.

\section{EDI IMPLEMENTATION}

To prepare integration of the EDI system with the corporate information system, certain information essential to integration and subsequent implementation must be known [6].

This is primarily information the provider should be given, i.e. data on the metallurgical company, details of the demands placed on EDI communication, and specifics about the information system. It is also important to have information about the business partners the company communicates with. The final step of integration is modification of the ERP for EDI communication.

Below is a list of the specific information the provider needs from the client requesting connection to EDI communication, in this case, the metallurgical company:

- Results of the analysis of current processes at the company. In the case of the metallurgical company, the provider will be given information from the analyses described in Chapter 3; in many other cases, the provider conducts the analyses itself.

- $\quad$ Preferred solution offered by the selected provider.

- GLN code.

- $\quad$ Contact person or persons for resolving EDI issues.

- Information about the ERP system: which system is involved, what outputs will be given to the provider (XML, position text file, IDOC, etc.), and samples and descriptions of messages which will be components of the EDI communication.

Other information required by the provider to configure EDI communication concerns the Dileris company's business partners, specifically:

- $\quad$ Whether the partner is EDI ready, i.e. already connected to EDI communication.

- Whether the partner is EDI ready. A sample of messages and their descriptions is required to determine any need for modifications in the translation templates. If a production variant or modification of translation templates becomes necessary, Dileris would incur additional costs because these modifications are above-standard services. Unfortunately, these services are not a part of the implementation package or monthly fee to operate the provider's services.

- Information about the ERP system: what type of system it is, what outputs will be given to the provider.

- $\quad$ Applied standard: e.g. EDIFACT (respectively, the EANCOM standard or other subsets of EDIFACT), ANSI, VDA, etc.

- $\quad$ EDI solution: direct interchange, VAN operator, provider, without integration - WebEDI. 
- In the case of a VAN operator solution, its business identification details to ensure connection, and in the case of an EDI provider solution, also its commercial name.

- $\quad$ GLN code.

- $\quad$ Contact person or persons for resolving EDI issues.

- $\quad$ Product identifiers (EAN codes, Part Numbers, own indicators).

For completeness, the steps which commonly follow the processes mentioned in this chapter are listed below. Because this article only addresses a proposal for implementation and the procedures below concern implementation itself, none of the given steps will be elaborated in detail.

Processes related to implementation:

- $\quad$ Testing EDI communication.

- Deployment of EDI or implementation of a separate solution.

- $\quad$ Pilot operation of EDI message interchange.

- Evaluation of trial operation.

- $\quad$ Launch of live EDI message interchange.

Data interchange requires approximately 1-3 months to fully implement (this includes a month of trial operation). This period is strongly subject to any required modifications to the corporate system and the specific requirements of the business partners. However, given the expertise and experience of technical support in modifying these information systems, the time required will most likely be less.

\section{EVALUATION OF THE EDI IMPLEMENTATION PROPOSAL}

This section discusses whether any advantages can be expected over the current solution and their extent. According to the SWOT analysis compiled and evaluated in the first section of this chapter, the strengths, weaknesses, opportunities and threats in the project undertaken in this paper will be described. The internal and external position of the project within the scenario will be evaluated.

In the first SWOT analysis of the metallurgical company (Figure 2), the six basic factors affecting electronic data interchange in each area in the proposed project are listed. These factors specifically concern the impact of the internal environment, which relates to strengths and weaknesses, and the impact of the external environment, which relates to the opportunities and threats in the venture.

The second SWOT analysis (Figure 3) indicates the evaluation results. Important information can be inferred from this evaluation.

To correctly express the resulting information from the SWOT analysis and for these results to be comprehensible by the other party, the steps which the author followed to reach the individual results are necessary to describe.

The first step assigned importance and value ranges to the individual SWOT analysis factors. Importance obeys the rule that the higher the number, the greater the importance, and that the sum of importance in each area must be equal to 1 . The value range is 1 to 4 , where 1 represents the worst assessment and 4 the best assessment.

The second step multiplied the individual importance scores and assessment values to obtain the resulting values whose sum is the SWOT analysis evaluation for each area.

From the resulting values, the individual factors were then arranged from the most important to the least important.

In the previous step, a SWOT matrix can also be deduced from the SWOT analysis evaluation and provide a method to select a suitable strategy. Factors with strategic importance and the selected optimal strategy are marked in bold outline. 
The next steps evaluated the external and internal environment factors, i.e. the EFE, IFE, and IE matrices. The key values from the results of these two analytical techniques are shown as the sum of internal and external environment impacts.

\begin{tabular}{|c|c|}
\hline \multicolumn{2}{|c|}{ SWOT analysis - Evaluation } \\
\hline Positive & Negative/Harmful \\
\hline STRENGTHS & WEAKNESSES \\
\hline Internal & \\
\hline $\begin{array}{l}\text { 1. ERP at a very high level. } \\
\text { 2. ERP created by an affiliated company. } \\
\text { 3. Technical support already has experience with } \\
\text { EDI implementation at an affiliated company. } \\
\text { 4. Some employees have experience with EDI } \\
\text { implementation. } \\
\text { 5. Very good supplier and customer base. } \\
\text { 6. Innovative thinking of employees. }\end{array}$ & $\begin{array}{l}\text { 1. Insufficient control of corporate processes. } \\
\text { 2. ERP functions are not fully used. } \\
\text { 3. Modification of product cards (especially spare } \\
\text { parts) in ERP to a usable format. } \\
\text { 4. Input costs for the EDI system. } \\
\text { 5. Insufficient communication between } \\
\text { departments. } \\
\text { 6. Need for additional ERP modifications for } \\
\text { possible EDI communications. }\end{array}$ \\
\hline OPPORTUNITIES & THREATS \\
\hline External & \\
\hline $\begin{array}{l}\text { 1. Fast and flawless data transfer from } \\
\text { documents directly to the corporate system. } \\
\text { 2. Prompt purchasing and fast sales. } \\
\text { 3. Cost savings for human resources and other } \\
\text { costs, e.g. consumables (paper, toner, etc.). } \\
\text { 4. Trade guaranteed in unlimited } 24 / 7 \text { mode. } \\
\text { 5. Acquisition of new customers and suppliers } \\
\text { and expanded cooperation with existing } \\
\text { customers and suppliers. } \\
\text { 6. Greater demand for purchasing goods through } \\
\text { the e-shop during the COVID- } 19 \text { pandemic. }\end{array}$ & $\begin{array}{l}\text { 1. Legislative changes in electronic commerce. } \\
\text { 2. Technically superior or new competition on the } \\
\text { market. } \\
\text { 3. Impact of the pandemic on the economy. } \\
\text { 4. General impact of COVID-19 pandemic on } \\
\text { trade. } \\
\text { 5. Infection or death of key project participant. } \\
\text { 6. Disruption of cyber security. }\end{array}$ \\
\hline
\end{tabular}

Figure 2 SWOT analysis of the metallurgical company: factors crucial in the EDI project

\begin{tabular}{|c|c|c|c|c|c|}
\hline \multicolumn{6}{|c|}{ SWOT analysis - Evaluation } \\
\hline \multicolumn{3}{|l|}{ Positive } & \multicolumn{3}{|l|}{ Negative/Harmful } \\
\hline \multicolumn{3}{|l|}{ STRENGTHS } & \multicolumn{3}{|l|}{ WEAKNESSES } \\
\hline Internal & Importance $\mathrm{E}$ & Evaluation & & Importance & Evaluation \\
\hline 1. Employee experience with EDI & 0.2 & 4 & 1. Input costs for the EDI system & 0.2 & 4 \\
\hline 2. Supplier-customer base & 0.2 & 3 & 2. Insufficient communication & 0.2 & 3 \\
\hline 3. Support experience with EDI & 0.2 & 3 & 3. Modification of product cards & 0.2 & 3 \\
\hline 4. High ERP level & 0.2 & 3 & 4. Insufficient control & 0.2 & 3 \\
\hline 5. ERP created byaffiliated company & 0.1 & 3 & 5. ERP functions are not fully used & 0.1 & 2 \\
\hline 6. Innovative thinking of employees & 0.1 & 3 & 6. Need for further ERP modifications & 0.1 & 2 \\
\hline TOTAL & 3.2 & & & 3 & \\
\hline \multicolumn{3}{|l|}{ OPPORTUNITIES } & \multicolumn{3}{|l|}{ THREATS } \\
\hline External & Importance E & Evaluation & & Importance & Evaluation \\
\hline 1. Cost savings & 0.2 & 4 & 1. Impact of pandemic on trade & 0.2 & 4 \\
\hline 2. Trade $24 / 7$ & 0.2 & 4 & 2. Competition on the market & 0.2 & 3 \\
\hline 3. Fast and flawless data transfer & 0.2 & 3 & 3. Infection or death of project team membe & er 0.2 & 3 \\
\hline 4. Prompt purchasing and fast sales & 0.2 & 3 & 4. Legislative changes in e-commerce & 0.2 & 2 \\
\hline 5. Purchases via e-shop due to pandemic & 0.1 & 4 & 5. Impact of pandemic on the economy & 0.1 & 3 \\
\hline 6. Acquisition of new customers & 0.1 & 3 & 6. Disruption of cyber security & 0.1 & 2 \\
\hline TOTAL & 3.5 & & & 2. & \\
\hline
\end{tabular}

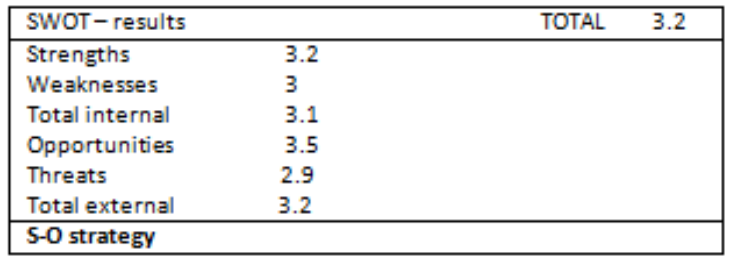

Figure 3 Evaluation of the SWOT analysis of the metallurgical company. 
The SWOT analysis identified the primary and most important factors of individual areas:

\section{- $\quad$ Strengths}

From the analysis, it may be inferred that the most important strength in the metallurgical company's project is the experience of certain employees with EDI. This may fundamentally affect and accelerate any future implementation if the company's employees can provide realistic ideas about the advantages and disadvantages of this form of electronic communication and the functionalities of the project. This may also be very helpful in supporting the project and gaining its approval from company management.

\section{- Weaknesses}

Another factor which impacts internally on the project is its weaknesses. The project's greatest weakness are the input costs of implementation, i.e. specifically the costs involved in adapting the ERP for communications capability in the EDI format. Unfortunately, these costs cannot be greatly adjusted if the EDI solution is required to deploy EDI communications under which the provider guarantees automated data interchange between the sender's and recipient's corporate systems.

\section{- Opportunities}

According to the SWOT analysis, the most fundamental opportunities from the external environment is in cost savings for human resources and other costs such as consumables and the possibility of unlimited $24 / 7$ trade ( 24 hours a day, 7 days a week). Both of these factors may result in an increase in the company's gross profit, which is one of the primary objectives of any enterprise.

\section{- $\quad$ Threats}

The final external factor critically affecting the metallurgical company's project is potential threats. The most substantial threat in the current circumstances is the general impact on trade of the COVID-19 disease pandemic caused by the SARS-CoV-2 coronavirus. Restrictive measures will lead to overall loss in trade and thus in the economy. General demand from the population in the foreseeable future will be very low, mainly due to the uncertain future of employment or business based on the mandatory closure or restriction of operation.

\section{- $\quad$ SWOT matrix}

The SWOT analysis lists several main factors which have an effect the company's project. These can also be used in another evaluation method to compile a SWOT matrix which can be used to select a suitable strategy.

\section{- $\quad$ S-O strategy}

Since opportunities (total 3.5) were rated highest in the external factors and strengths (total 3.2) were rated highest in the internal factors, an S-O strategy is recommended. This strategy is a usage strategy characterised by an aggressive approach which exploits the strengths of the company's project in favour of its opportunities. The strategy defines a desired outcome which it is geared towards. The metallurgical company should take advantage of the opportunities highlighted by the SWOT analysis by applying its identified strengths.

Specifically, the metallurgical company can save costs in implementing EDI by exploiting the experience of its employees and technical support in introducing EDI communications. The experience of these employees can contribute to faster implementation and reduce very probable additional costs.

The final step in evaluating the SWOT analysis calculated the evaluation matrix of the internal and external factors. 


\section{IFE MATRIX}

The IFE matrix is an analytical method linked to SWOT analysis. The results of this method indicate either the organisation's internal position, or in this case, its strategic project.

From the results of the SWOT analysis, the IFE matrix is created by adding up the weighted ratios of the individual internal factors. The result is the overall weighted ratio. This weighted ratio indicates the internal position of the organisation's strategic project. The best possible score is 4 and the worst is 1 . The median value is approximately 2.5 .

In the case of the metallurgical company's project, the overall weighted ratio is a value of 3.1 . This means the enterprise's project is supported by a relatively strong internal position.

\section{EFE MATRIX}

The EFE matrix is an analytical method also linked to SWOT analysis. The results of this method indicate either the organisation's external position, or in this case, its strategic project.

From the results of the SWOT analysis, the EFE matrix is created by summing the weighted ratios of the individual external factors. The result is the overall weighted ratio. This weighted ratio indicates the external position of the organisation's strategic project. This method of evaluation applies the same characteristics as the IFE matrix.

In the case of the Dileris company's project, the overall weighted ratio is a value of 3.2. This means that the enterprise's project is supported by a relatively strong external position.

The results of the IFE and EFE matrix are then combined. The IE matrix, which is defined as the internalexternal matrix, incorporates the results of the EFE and IFE matrices and provides an indication of the aforementioned internal and external factors [7].

\section{EVALUATION OF THE IFE AND EFE MATRICES: IE MATRIX}

The IE matrix (Figure 4) is generated by entering the IFE matrix results along the $x$-axis and the EFE matrix results along the $y$-axis. The IE matrix results shows nine fields. These fields can be divided into three main areas. These fields and areas are depicted and described in the figure below.

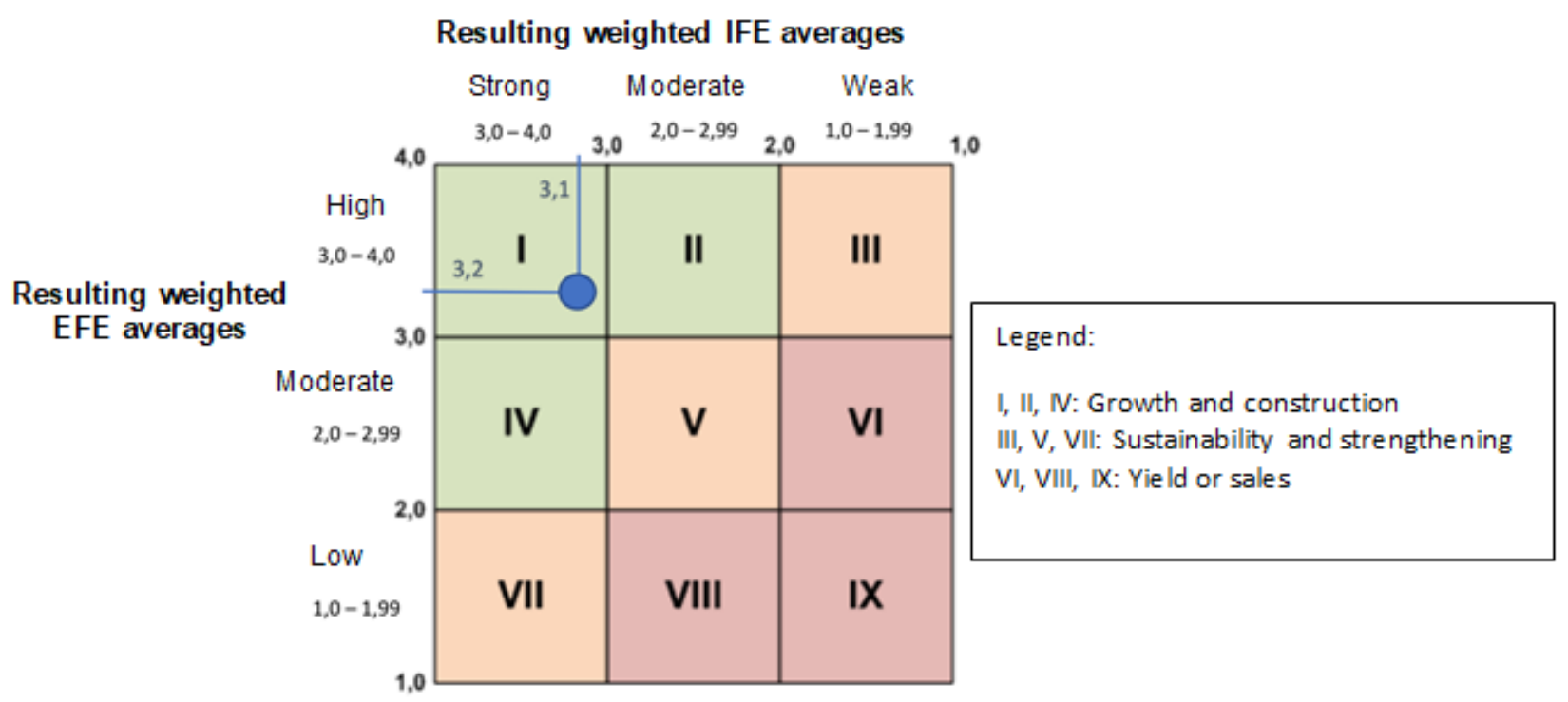

Figure 4 IE matrix 
The IE matrix indicates the strongest result in quadrant I, which is growth and building. The recommended strategies are product development, market development, vertical and horizontal integration and investment strategy. Hence, the company's position is absolutely ideal for EDI implementation.

\section{CONCLUSION}

The results of the analysis indicate that implementing an EDI system into the existing ERP information system would be appropriate for the metallurgical company.

The form of trans-network communications is appropriate for use in electronic data interchange. An essential component of the future EDI communications solution is a GLN identification number. This number identifies the company in the EDI world.

In the integration phase, obtaining all the information required by the provider is essential and will ensure swifter progress in implementation. This information contains details about the metallurgical company and the business partners it will communicate with through EDI and is essential for modifying the information system for EDI communication.

\section{ACKNOWLEDGEMENTS}

The work was supported by the specific university research of Ministry of Education, Youth and Sports of the Czech Republic No. SP2020/60.

\section{REFERENCES}

[1] SUCHÁNEK, P. E-commerce: elektronické podnikání a koncepce elektronického obchodování. Praha: Ekopress, 2012.

[2] CHAFFEY, D., EDMUNDSON-BIRD, D., HEMPHILL, T. Digital business and e-commerce management: strategy, implementation and practice. New York: Pearson, 2019.

[3] REICHEL, D. Jak na elektronickou výměnu dat (EDI)?. Brno: CCV Informační systémy, 2009.

[4] Jak zavést EDI? EDIZone - Vše co potřebujete vědět o EDI - elektronické výměně dat [online]. [viewed 2020-0105]. Available from: http://www.edizone.cz/elektronicka-vymena-dat/jak-zavest-edi/.

[5] LAUDON, K. C., LAUDON, J. P. Management Information Systems. Upper saddle River, New Jersey: Pearson Publishing, 2010.

[6] COHEN, R. P. EDI Basics: How successful businesses connect, communicate, and collaborate around the world [online]. Gaithersburg: GXS, 2017 [viewed 2019-11-20]. Available form: https://www.edibasics.com/ediresources/edi-basics/.

[7] JUREVICIUS, O. IFE \& EFE Matrices [online]. [viewed 2020-04-30]. Available form: https://strategicmanagementinsight.com/tools/ife-efe-matrix.html. 